\title{
INFLUÊNCIA DA CARGA CIRCULANTE DO PELOTAMENTO NA QUALIDADE FÍSICA DAS PELOTAS CRUAS E QUEIMADAS DA SAMARCO MINERAÇÃO*
}

\author{
Sérgio Fernando Nunes ${ }^{1}$ \\ Cláudio Batista Vieira² \\ Cláudio Luis Goulart ${ }^{3}$ \\ Maurício Cota Fonseca ${ }^{4}$
}

\section{Resumo}

No presente estudo foi realizada uma investigação da influência do teor de hematita especular, percentual e granulometria da carga circulante do pelotamento nos parâmetros de qualidade física das pelotas cruas e queimadas de minério de ferro da Samarco Mineração. Preliminarmente foram executados testes exploratórios em escalas de laboratório e industrial objetivando avaliar o melhor teor de umidade, área superficial específica do pellet feed e carga circulante do pelotamento. Após essa fase exploratória, foi feito o projeto de experimentos dos ensaios de pelotamento e de queima no pot grate, empregando três fatores em dois níveis com ponto central e réplica. A resistência á compressão a úmido e a seco, diâmetro médio e bulk density, foram os parâmetros de qualidade física avaliados para as pelotas cruas. A resistência á compressão, índice de tamboramento e abrasão, porosidade e bulk density, foram os parâmetros de qualidade física avaliados para as pelotas queimadas. O atributo percentual de pelotas nucleadas queimadas também foi avaliado. Concluiu-se que a mineralogia, granulometria do pellet feed e composição da carga circulante influenciam fortemente na qualidade física das pelotas cruas e queimadas.

Palavras-chave: Minério de ferro; Pelotamento; Carga circulante; Pelotização.

\section{INFLUENCE OF PELLETIZING CIRCULATION LOAD ON THE PHYSICAL QUALITY OF GREEN AND FIRED PELLETS FROM SAMARCO MINING}

\section{Abstract}

In this paper, a large investigation was made about the specular hematite content influence and the percentage and size of the circulation load on the green pellets physical quality of Samarco's iron ore. Exploratory tests were executed in industrial and laboratory scale searching the best moisture content and specific surface area of the pellet feed and circulation load researched. After this, the experimental plan in pilot scale was made based on three factors divided in two levels with replica design and center point. The experimental tests developed were green ball formation and thermal green pellets induration using Samarco's pilot plant. Compression resistance in the wet and dry way, average diameter and bulk density were the physical properties evaluated for green pellets. The compression resistance, the tumbling and abrasion indicators, porosity and bulk density were the physical properties evaluated for the fired pellets. The percentage parameter for the core fired pellets was also evaluated. It was made clear that mineralogy, pellet feed's size and circulation load composition have strongly influence on green and fired physical quality Samarco's pellets.

Keywords: Iron ore; Green ball formation; Circulation load; Pelletizing.

1 Engenheiro Metalurgista, M. Sc., Engenheiro Especialista Sênior, Gerência Geral Operações, Samarco Mineração S/A, Anchieta, Espirito Santo, Brasil.

2 Engenheiro Metalurgista, Prof. Dr., DEMET- Escola de Minas UFOP / Redemat, Ouro Preto, Minas Gerais, Brasil.

3 Engenheiro Metalurgista, M. Sc., Engenheiro Especialista Sênior, Gerência Geral Engenharia de Planejamento e Controle, Samarco Mineração S/A, Anchieta, Espirito Santo, Brasil.

4 Engenheiro Metalurgista, M. Sc., Engenheiro Especialista Sênior, Gerência Geral de Tecnologia e Ecoeficiência, Samarco Mineração S/A, Anchieta, Espirito Santo, Brasil.

* Contribuição técnica ao 44 Seminário de Redução de Minério de Ferro e Matérias-primas, $15^{\circ}$ Simpósio Brasileiro de Minério de Ferro e $2^{\circ}$ Simpósio Brasileiro de Aglomeração de Minério de Ferro, 15 a 18 de setembro de 2014, Belo Horizonte, MG, Brasil. 


\section{INTRODUÇÃO}

A Samarco Mineração S/A é uma empresa mineradora e grande fornecedora mundial de pelotas. É constituída de duas unidades, Germano - M.G (mina e concentração), e Ubu - E.S (pelotização e porto), que estão ligadas por três minerodutos. A capacidade de produção é de 30,5 milhões toneladas de pelotas queimadas por ano.

As jazidas de minério de ferro da Samarco são constituídas de itabiritos hematíticos hidratados e estão situadas no Complexo de Alegria (MG). A hematita martítica é o constituinte mineralógico mais abundante, seguida pela hematita especular, goethita e magnetita em menor proporção. O teor médio de hematita especular do Complexo de Alegria é de 25\% [1]. Através de lavra seletiva, o teor de hematita especular dos concentrados produzidos é de $40 \%$ para atendimento às especificações da pelotização.

Os constituintes mineralógicos influenciam fortemente na qualidade física das pelotas cruas e queimadas. Quanto maior o teor de hematita especular melhor será a qualidade física das pelotas cruas e queimadas [2-5] Portanto, este fator explica as razões para a prática de lavra seletiva utilizada pela Samarco. A granulometria do pellet feed também influencia fortemente na qualidade física das pelotas cruas e queimadas. Quanto maior a área superficial específica do pellet feed, melhor será a qualidade física das pelotas cruas e queimadas [2,3,6-9].

As pelotas e aglomerados de forma indefinida que possuem tamanho menor que $8 \mathrm{~mm}$ e maior que $18 \mathrm{~mm}$ (indesejáveis) são separados por mesas classificadoras e transportados por correias para compor a carga circulante do pelotamento. Esta carga circulante corresponde, em torno de $20 \%$ do material que é alimentado no disco de pelotamento e apresenta granulometria mais grosseria comparando-se com o pellet feed, interferindo no processo de formação das pelotas cruas e contribuindo para a perda de qualidade física das pelotas cruas e queimadas.

Nesse estudo, foi realizada uma investigação da influência do teor de hematita especular, percentual e granulometria da carga circulante do pelotamento nos parâmetros de qualidade física das pelotas cruas e queimadas de minério de ferro da Samarco Mineração.

\section{MATERIAIS E MÉTODOS}

A metodologia utilizada na condução dos trabalhos é apresentada no fluxograma da Figura 1.

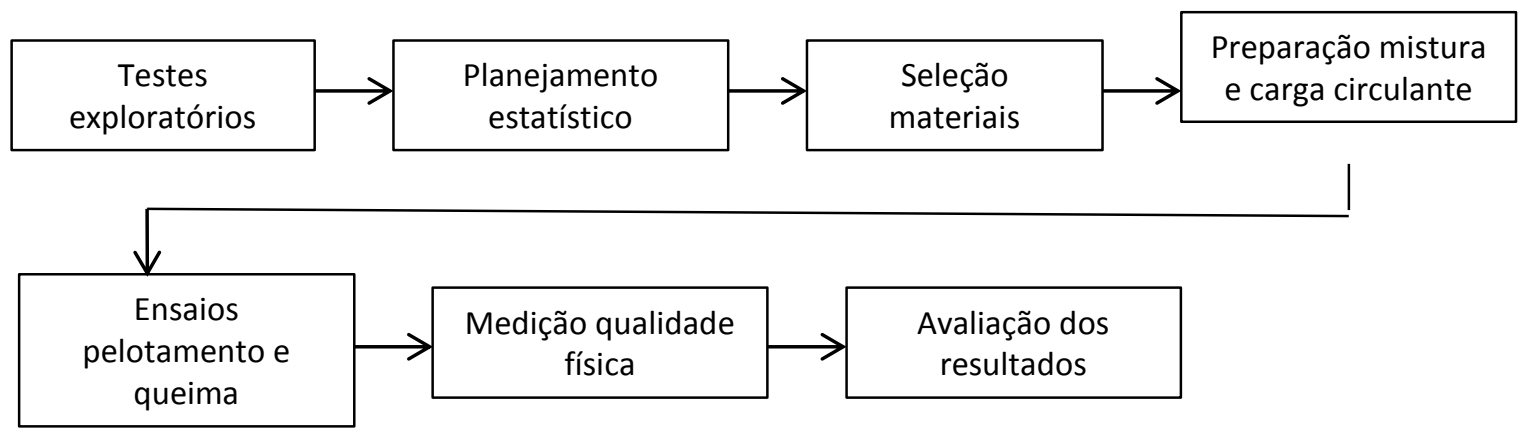

Figura 1. Fluxograma das Atividades Desenvolvidas.

\footnotetext{
* Contribuição técnica ao 44ำ Seminário de Redução de Minério de Ferro e Matérias-primas, $15^{\circ}$ Simpósio Brasileiro de Minério de Ferro e 2º Simpósio Brasileiro de Aglomeração de Minério de Ferro, 15 a 18 de setembro de 2014, Belo Horizonte, MG, Brasil.
} 


\subsection{Testes Exploratórios}

Os testes exploratórios foram executados como forma de melhor reproduzir o processo industrial para os ensaios de pelotamento e queima. Consistiram em ensaios em escala de laboratório (bancada) e industrial, objetivando:

- Identificar a diferença do teor de umidade da mistura (pellet feed e insumos) e carga circulante;

- Identificar a área superficial específica para os testes principais;

- Adequar o melhor teor de umidade;

- Correlacionar os dados industriais de qualidade física da pelota queimada com o teor de hematita especular do pellet feed.

\subsection{Planejamento Estatístico dos Experimentos em Escala Piloto}

A Tabela 1 apresenta o projeto de experimentos com três fatores sendo: teor hematita especular, percentual e granulometria da carga circulante do pelotamento. As réplicas e pontos centrais também compuseram o planejamento estatístico dos testes. O teor de hematita especular apresentou três níveis sendo $51 \%$, 39\% e $28 \%$. A carga circulante apresentou três níveis sendo: $10 \%, 20 \%$ e $30 \%$. A granulometria da carga circulante ficou classificada em grosso (diâmetro de 5,09mm), média (diâmetro de $4,35 \mathrm{~mm}$ ) e fina (diâmetro de $3,15 \mathrm{~mm}$ ). As variáveis respostas estudadas foram: resistência a compressão das pelotas cruas úmidas, secas (CPCU, CPCS) e queimadas (CCS), quantidade de pelotas nucleadas, bulk density das pelotas cruas e queimadas, diâmetro médio das pelotas cruas, índice de tamboramento e abrasão e porosidade das pelotas queimadas.

Tabela 1. Planejamento do Projeto de Experimentos

\begin{tabular}{c|c|c|c|c}
\hline Ordem & Bloco & Hematita especular & Quantidade carga circulante & Granulometria retorno \\
\hline 1 & 1 & 51 & 10 & grosso \\
\hline 2 & 1 & 28 & 10 & fino \\
\hline 3 & 1 & 51 & 30 & fino \\
\hline 4 & 1 & 51 & 10 & fino \\
\hline 5 & 1 & 28 & 30 & grosso \\
\hline 6 & 1 & 28 & 30 & médio \\
\hline 7 & 1 & 39 & 20 & grosso \\
\hline 8 & 1 & 51 & 30 & grosso \\
\hline 9 & 1 & 28 & 10 & grosso \\
\hline 10 & 2 & 51 & 10 & fino \\
\hline 11 & 2 & 28 & 10 & fino \\
\hline 12 & 2 & 51 & 30 & fino \\
\hline 13 & 2 & 51 & 10 & fino \\
\hline 14 & 2 & 28 & 30 & grosso \\
\hline 15 & 2 & 28 & 30 & médio \\
\hline 16 & 2 & 39 & 20 & grosso \\
\hline 17 & 2 & 51 & 30 & grosso \\
\hline 18 & 2 & 28 & 10 & \\
\hline
\end{tabular}

\subsection{Seleção dos Materiais Utilizados}

Para a obtenção do teor de baixa hematita especular foi constituída amostra de minério na mina de Alegria (ROM) e enviada a laboratório terceirizado para concentração onde ocorreu o processo de flotação. A amostra de alto teor de hematita especular foi coletada na planta industrial após a etapa de filtragem, antes da prensagem em prensa de rolos. O concentrado com teor médio de hematita

* Contribuição técnica ao 44 Seminário de Redução de Minério de Ferro e Matérias-primas, $15^{\circ}$ Simpósio Brasileiro de Minério de Ferro e $2^{\circ}$ Simpósio Brasileiro de Aglomeração de Minério de Ferro, 15 a 18 de setembro de 2014, Belo Horizonte, MG, Brasil. 
especular foi constituído da blendagem de partes iguais de pellet feed de baixo teor de hematita com o de alto teor. Os insumos utilizados nas pelotas cruas foram coletados nas linhas de mistura das usinas de pelotização da empresa.

\subsection{Preparação da Mistura e Desagregação da Carga Circulante}

As misturas de pellet feed com os aditivos foram preparadas em misturador vertical. A velocidade do misturador foi ajustada para evitar aglomeração e quebra dos aglomerados da carga circulante. A carga circulante foi produzida inicialmente no disco piloto e posteriormente foi desagregada em peneiras utilizando-se espátulas. Esta desagregação foi necessária, pois o formato dos aglomerados que compõem a carga circulante são irregulares. Para compor a granulometria da carga circulante foram escolhidas peneiras com aberturas de $6,3 \mathrm{~mm}, 4,65 \mathrm{~mm}$ e $3,15 \mathrm{~mm}$. A Figura 2 apresenta o formato dos aglomerados desagregados nas peneiras.

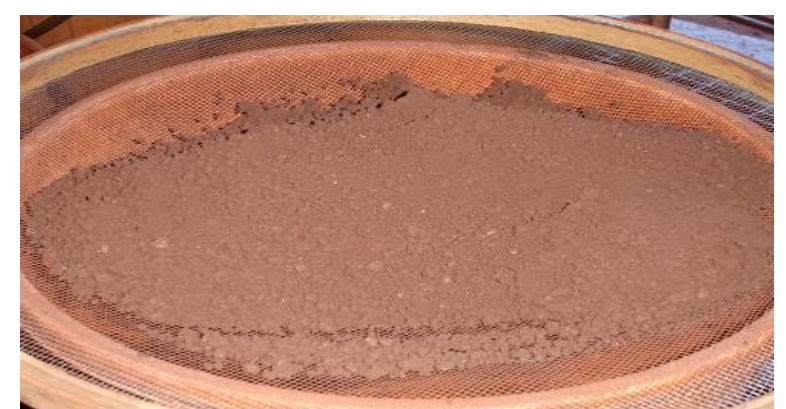

Figura 2. Material da Carga Circulante com Formatos Aleatórios.

\subsection{Ensaios de Pelotamento e Queima}

$\mathrm{Na}$ avaliação da etapa de pelotamento em disco piloto, foram utilizados $280 \mathrm{~kg}$ de cada amostra de pellet feed para composição da mistura a aglomerar, conforme o planejamento do projeto de experimentos. Para cada amostra gerada de pellet feed e carga circulante, produziram-se em um disco de pelotamento piloto, as pelotas cruas. Anteriormente o pellet feed, insumos e carga circulante foram misturados em um misturador vertical. O pot grate é um equipamento piloto, planejado para simular o ciclo térmico utilizado industrialmente no processo de endurecimento ou queima das pelotas cruas. Os seus principais componentes são: câmara de combustão, panela, caixa de vento, coifa, sistema de controle e programa computacional que permite a simulação do tempo de permanência das pelotas nas zonas de secagem, de queima e resfriamento, em função do ritmo de produção.

\subsection{Medição da Qualidade Física das Pelotas Cruas e Queimadas}

Os testes para avaliação da qualidade física das pelotas cruas e queimadas basearam-se em metodologias desenvolvidas internamente bem como em padrões internacionais (normas ISO). Destaca-se a medição da quantidade de pelotas nucleadas e testes de microdureza. A análise de nucleação consistiu na identificação visual de sementes presentes no interior das pelotas queimadas (Figuras 3 e 4). As pelotas são provenientes dos testes de resistência à compressão. As pelotas então são classificadas de nucleadas ou não nucleadas e também são correlacionadas com a sua resistência a compressão.

\footnotetext{
* Contribuição técnica ao 44ํ Seminário de Redução de Minério de Ferro e Matérias-primas, $15^{\circ}$ Simpósio Brasileiro de Minério de Ferro e $2^{\circ}$ Simpósio Brasileiro de Aglomeração de Minério de Ferro, 15 a 18 de setembro de 2014, Belo Horizonte, MG, Brasil.
} 


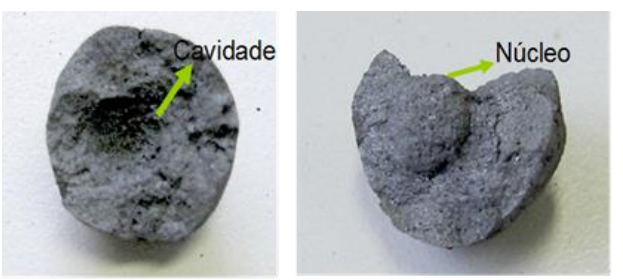

Figura 3. Pelota Queimada Nucleada
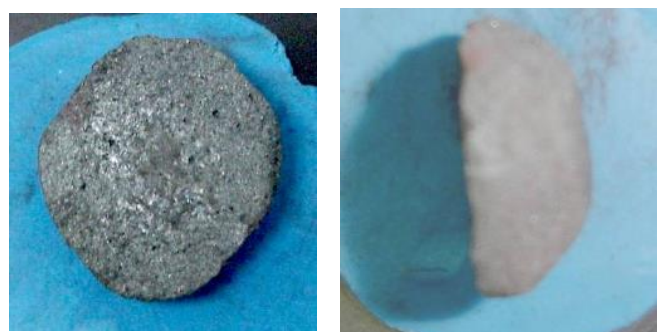

Figura 4. Pelota Queimada sem Núcleo.

Os testes de microdureza foram executados no equipamento da marca Leitz. O equipamento consiste em um penetrador com carga fixa em $100 \mathrm{~g}$ aplicada. $\mathrm{O}$ tempo de aplicação foi de 30s para cada teste no intervalo de $0,25 \mathrm{~mm}$ de borda a borda da pelota queimada. A dureza medida está em HV (dureza Vickers).

\section{RESULTADOS E DISCUSSÕES}

\subsection{Testes Exploratórios}

O teor de umidade da carga circulante é menor comparando-se com a mistura em $0,3 \%$. As 30 amostras coletadas industrialmente e simultaneamente comprovam esta diferença. Os resultados são apresentados na Figura 5.

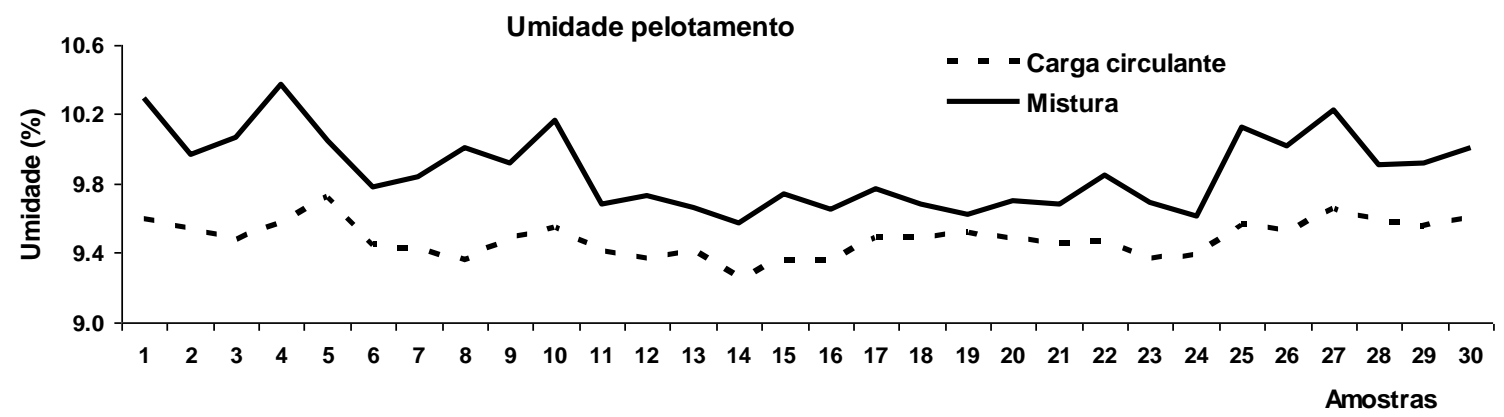

Figura 5. Dados Comparativos da Umidade da Mistura e da Carga Circulante

O menor teor de umidade da carga circulante é comprovado pelo teor de umidade dos aglomerados descarregados dos discos. A Figura 6 apresenta dados industriais com boa correlação entre aglomerados e pelotas cruas descarregados de um disco e seu teor de umidade. 

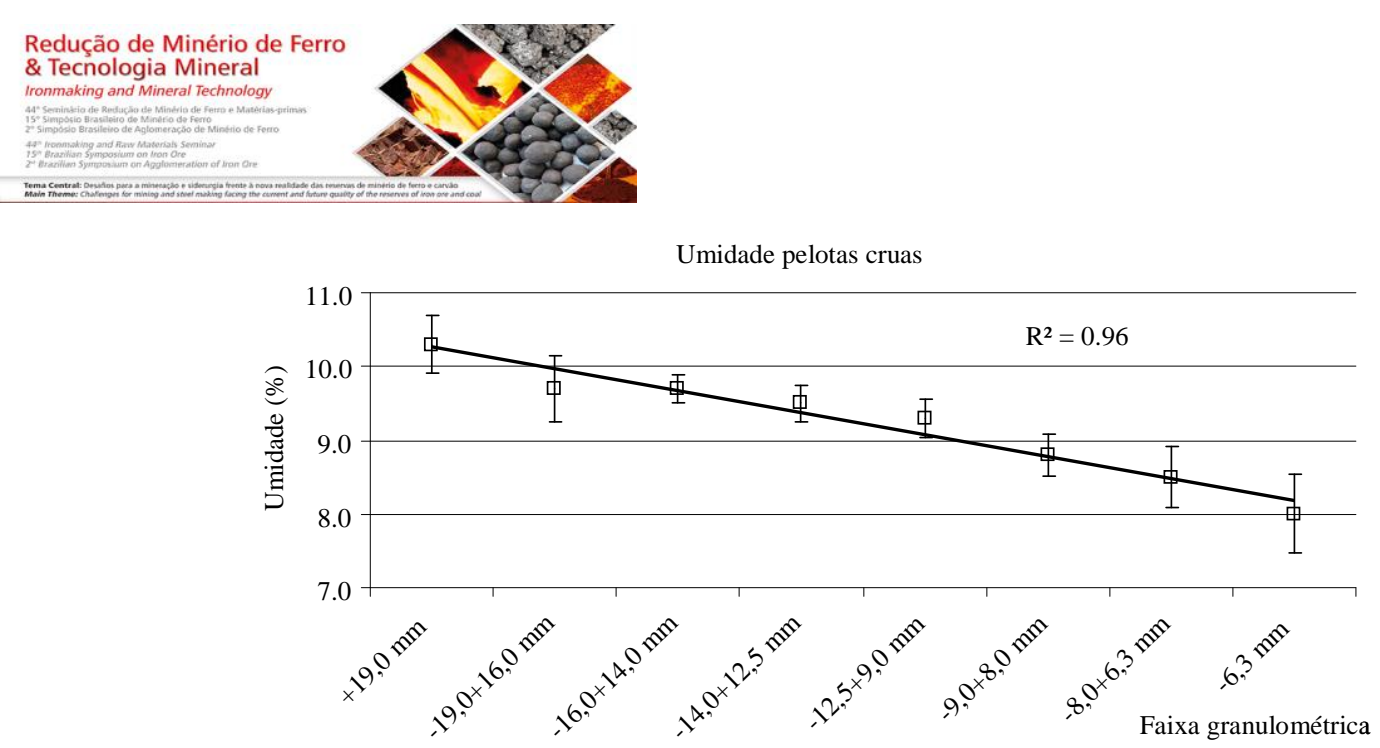

Figura 6. Análise Estatística entre o Teor de Umidade e a Distribuição Granulométrica de Pelotas Cruas e Aglomerados da Descarga dos Discos.

Observa-se que quanto maior o percentual de carga circulante maior a quantidade de pequenos aglomerados secos e, portanto menor é o teor de umidade. Este fato é um grande problema já que a aglomeração depende da umidade em torno das partículas para a formação das forças capilares [2,3,7], consequentemente há um desequilíbrio, ou seja, dentro de um disco existem pelotas com mais água em torno da partícula do que outras. Quando o material mais seco torna-se uma semente e ou participa do crescimento de um aglomerado, significa que menos capilares serão formados e consequentemente será menos resistente e de menor diâmetro.

$\mathrm{Na}$ Tabela 3 são apresentados as áreas superficiais específicas e os teores de umidade obtidos nos testes exploratórios.

Tabela 3. Teste Exploratório com Variação de Área Superficial Específica.

\begin{tabular}{c|c}
\hline Superfície específica $\left.\mathbf{g} / \mathrm{cm}^{2}\right)$ & Umidade (\%) \\
\hline 2100 & 9.3 \\
\hline 2420 & 9.3 \\
\hline
\end{tabular}

A Figura 7 apresenta as pelotas produzidas com cada área superficial especifica desses testes exploratórios. Na figura $7(b)$ as pelotas apresentaram uma tendência de colamento entre si. Para comprovar este efeito de colamento as pelotas cruas da Figura 7(b) foram queimadas no pot grate. A Figura 8 apresenta os resultados, confirmando o mesmo efeito nas pelotas queimadas. Portanto a área superficial específica escolhida para a continuidade dos testes em escala piloto foi de $2100 \mathrm{~cm}^{2} / \mathrm{g}$.

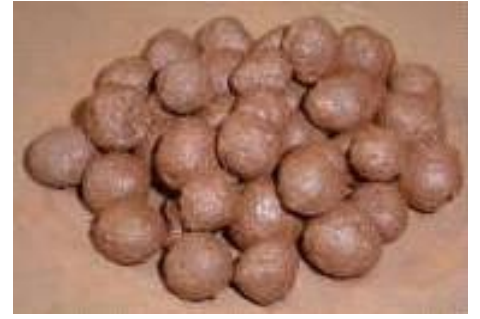

(a) $2100 \mathrm{~cm}^{2} / \mathrm{g}$

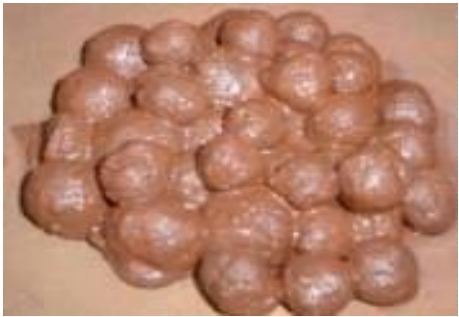

(b) $2400 \mathrm{~cm}^{2} / \mathrm{g}$

Figura 7. (a) Pelotas Cruas Ideais e (b) Pelotas Cruas com Comportamento Plástico.

* Contribuição técnica ao $44^{\circ}$ Seminário de Redução de Minério de Ferro e Matérias-primas, $15^{\circ}$ Simpósio Brasileiro de Minério de Ferro e $2^{\circ}$ Simpósio Brasileiro de Aglomeração de Minério de Ferro, 15 a 18 de setembro de 2014, Belo Horizonte, MG, Brasil. 


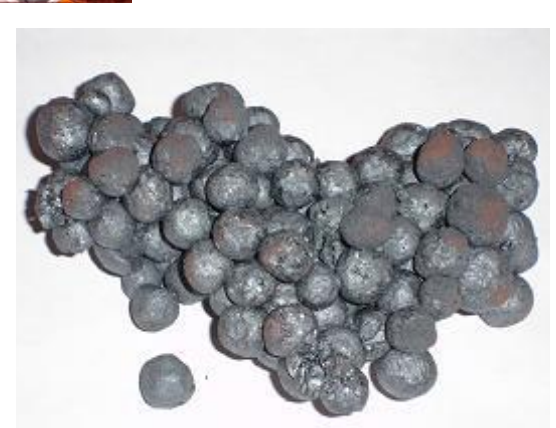

Figura 8. Pelotas Queimadas do Teste Exploratório com Alta Área Superficial Específica.

A Figura 9 apresenta um gráfico com os resultados de pelotamentos com diversos teores de umidade para os concentrados com alto, médio e baixo teor de hematita especular. As umidades escolhidas para os testes levaram em consideração os melhores resultados de compressão a seco (CPCS). Portanto, os teores de umidade escolhidos respectivamente foram 10,6\%, 9,8\% e $9 \%$.

\section{RESISTÊNCIA PELOTA CRUA X UMIDADE}

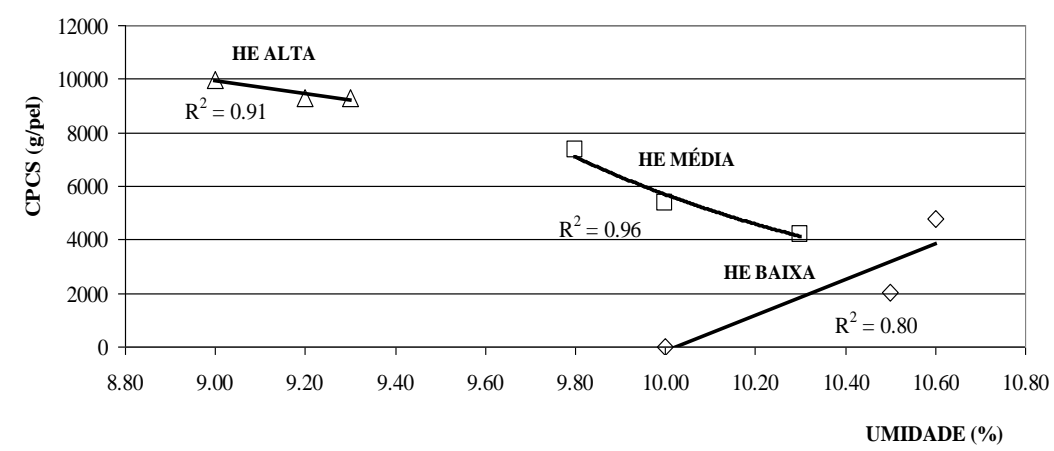

Figura 9. Resultados dos Testes Exploratórios: Teor de Umidade Versus Resistência CPCS.

A Figura 10 apresenta a curva de correlação entre teor de hematita especular do pellet feed e a resistência a compressão das pelotas queimadas. Observa-se, com alto $R^{2}$, que quanto maior o teor de hematita especular maior é a resistência a compressão das pelotas queimadas.

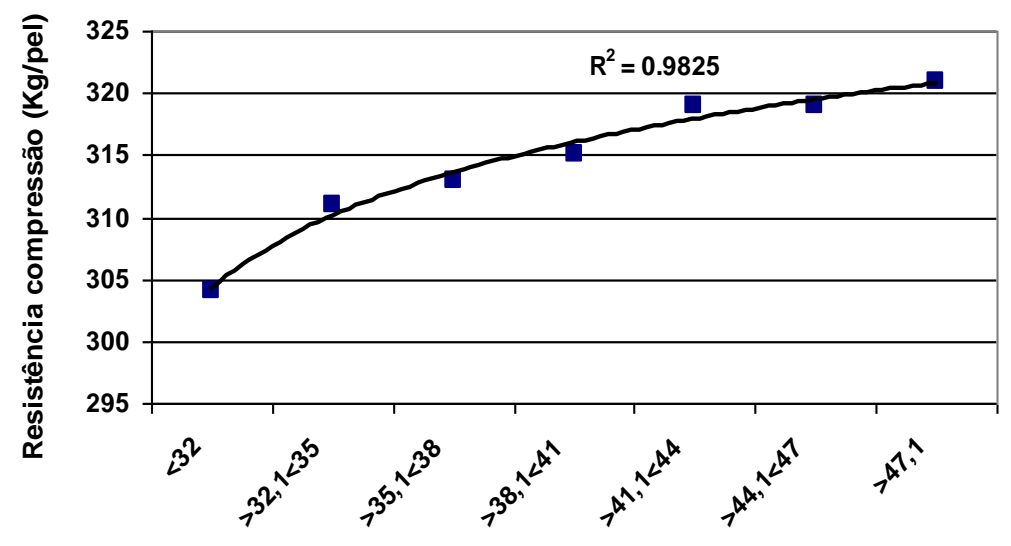

Hematita especular (\%)

Figura 10. Valores de Resistência à Compressão versus \% Hematita Especular do Pellet Feed (Fonte: Dados Industriais Samarco).

* Contribuição técnica ao 44ำ Seminário de Redução de Minério de Ferro e Matérias-primas, $15^{\circ}$ Simpósio Brasileiro de Minério de Ferro e 2º Simpósio Brasileiro de Aglomeração de Minério de Ferro, 15 a 18 de setembro de 2014, Belo Horizonte, MG, Brasil. 


\subsection{Ensaios de Pelotamento e de Queima em Planta Piloto}

As Tabelas 3 e 4 apresentam os resultados dos ensaios de pelotamento e de queima. Nas Figuras 11 e 12 são apresentadas as interações estatísticas.

Tabela 3. Resultados dos Ensaios de Pelotamento em Escala Piloto.

\begin{tabular}{c|c|c|c|c|c|c|c}
\hline TESTES & Mineralogia (\%) & $\begin{array}{c}\text { Carga circulante } \\
(\%)\end{array}$ & $\begin{array}{c}\text { Granulometria } \\
\text { carga circulante }\end{array}$ & $\begin{array}{c}\text { Bulk density pelota } \\
\text { crua (g/cm })\end{array}$ & $\begin{array}{c}\text { Diâmetro } \\
\text { médio }(\mathbf{m m})\end{array}$ & CPCU (g/pel) & CPCS (g/pel) \\
\hline 1 & HE alta & 10 & grosso & 2,15 & 11,3 & 2305 & 9210 \\
\hline 2 & HE baixa & 30 & fino & 1,95 & 8,2 & 2158 & 3644 \\
\hline 3 & HE alta & 30 & fino & 2,13 & 10,8 & 2202 & 8931 \\
\hline 4 & HE baixa & 30 & grosso & 1,96 & 8,0 & 2066 & 3205 \\
\hline 5 & HE média & 20 & médio & 2,05 & 9,8 & 2070 & 7339 \\
\hline 6 & HE baixa & 10 & grosso & 1,96 & 8,5 & 2008 & 3810 \\
\hline 7 & HE alta & 30 & grosso & 2,14 & 10,5 & 2233 & 8740 \\
\hline 8 & HE alta & 10 & fino & 2,14 & 11,5 & 2088 & 10445 \\
\hline 9 & HE baixa & 10 & fino & 1,99 & 8,8 & 1860 & 4801 \\
\hline 10 & HE alta & 10 & grosso & 2,13 & 11,0 & 2166 & 9665 \\
\hline 11 & HE baixa & 30 & fino & 1,97 & 9,0 & 1934 & 3678 \\
\hline 12 & HE alta & 30 & fino & 2,14 & 10,6 & 2202 & 9295 \\
\hline 13 & HE baixa & 30 & grosso & 1,95 & 8,3 & 1829 & 3480 \\
\hline 14 & HE média & 20 & médio & 2,04 & 9,6 & 2203 & 7775 \\
\hline 15 & HE baixa & 10 & grosso & 1,96 & 8,4 & 2017 & 5257 \\
\hline 16 & HE alta & 30 & grosso & 2,12 & 9,4 & 2133 & 8315 \\
\hline 17 & HE alta & 10 & fino & 2,18 & 11,5 & 2197 & 9986 \\
\hline 18 & HE baixa & 10 & fino & 1,98 & 9,4 & 1767 & 5181 \\
\hline
\end{tabular}

Tabela 4. Resultados dos Ensaios de Queima em Escala Piloto.

\begin{tabular}{|c|c|c|c|c|c|c|c|c|}
\hline Mineralogia (\%) & $\begin{array}{c}\text { Carga } \\
\text { circulante (\%) }\end{array}$ & $\begin{array}{c}\text { Granulometria } \\
\text { carga circulante }\end{array}$ & $\begin{array}{c}\text { Resistencia } \\
\text { compressão } \\
\text { CCS (kg/pel) }\end{array}$ & $\begin{array}{c}\text { Índice de } \\
\text { tamboramento } \\
(\%)\end{array}$ & $\begin{array}{c}\text { Índice de } \\
\text { abrasão (\%) }\end{array}$ & $\begin{array}{c}\text { Pelotas } \\
\text { queimadas } \\
\text { nucleadas } \\
(\%)\end{array}$ & $\begin{array}{c}\text { Porosidade das } \\
\text { pelotas } \\
\text { queimadas }(\%)\end{array}$ & $\begin{array}{c}\text { Bulk density } \\
\text { pelota } \\
\text { queimada } \\
\left(\mathrm{g} / \mathrm{cm}^{3}\right)\end{array}$ \\
\hline HE alta & 10 & grosso & 331 & 96,2 & 3,2 & 50 & 28,6 & 2,09 \\
\hline HE baixa & 30 & fino & 277 & 92,7 & 6,1 & 49 & 33,0 & 1,93 \\
\hline HE alta & 30 & fino & 350 & 95,9 & 3,4 & 63 & 28,3 & 2,08 \\
\hline HE baixa & 30 & grosso & 261 & 92,6 & 6,2 & 70 & 32,9 & 1,94 \\
\hline HE média & 20 & médio & 311 & 95,8 & 3,6 & 53 & 31,2 & 2,02 \\
\hline HE baixa & 10 & grosso & 277 & 92,7 & 6,0 & 45 & 32,5 & 1,94 \\
\hline HE alta & 30 & grosso & 324 & 95,7 & 3,5 & 61 & 28,5 & 2,08 \\
\hline HE alta & 10 & fino & 364 & 96,6 & 2,9 & 43 & 28,1 & 2,09 \\
\hline HE baixa & 10 & fino & 287 & 93,0 & 5,7 & 29 & 31,9 & 2,02 \\
\hline HE alta & 10 & grosso & 342 & 96,0 & 3,4 & 35 & 28,5 & 2,06 \\
\hline HE baixa & 30 & fino & 268 & 92,3 & 6,0 & 51 & 32,6 & 1,94 \\
\hline HE alta & 30 & fino & 326 & 95,9 & 3,5 & 35 & 28,1 & 2,07 \\
\hline HE baixa & 30 & grosso & 255 & 92,1 & 6,7 & 66 & 33,1 & 1,90 \\
\hline HE média & 20 & médio & 301 & 95,1 & 3,7 & 48 & 30,1 & 2,01 \\
\hline HE baixa & 10 & grosso & 272 & 93,0 & 5,6 & 44 & 32,4 & 1,94 \\
\hline HE alta & 30 & grosso & 337 & 95,8 & 3,6 & 42 & 28,7 & 2,03 \\
\hline HE alta & 10 & fino & 375 & 96,8 & 2,7 & 33 & 28,3 & 2,12 \\
\hline HE baixa & 10 & fino & 272 & 92,9 & 5,9 & 29 & 32,1 & 1,95 \\
\hline
\end{tabular}
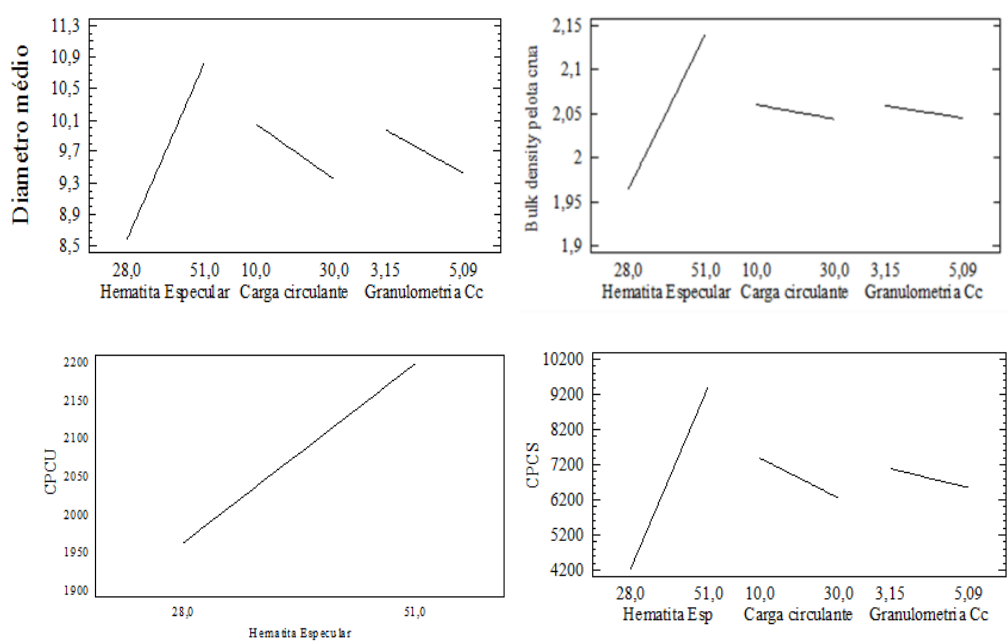

Figura 11. Interações dos Parâmetros de Qualidade Física das Pelotas Cruas com os Fatores.

* Contribuição técnica ao 44ํㅗㄴ Seminário de Redução de Minério de Ferro e Matérias-primas, $15^{\circ}$ Simpósio Brasileiro de Minério de Ferro e 2º Simpósio Brasileiro de Aglomeração de Minério de Ferro, 15 a 18 de setembro de 2014, Belo Horizonte, MG, Brasil. 

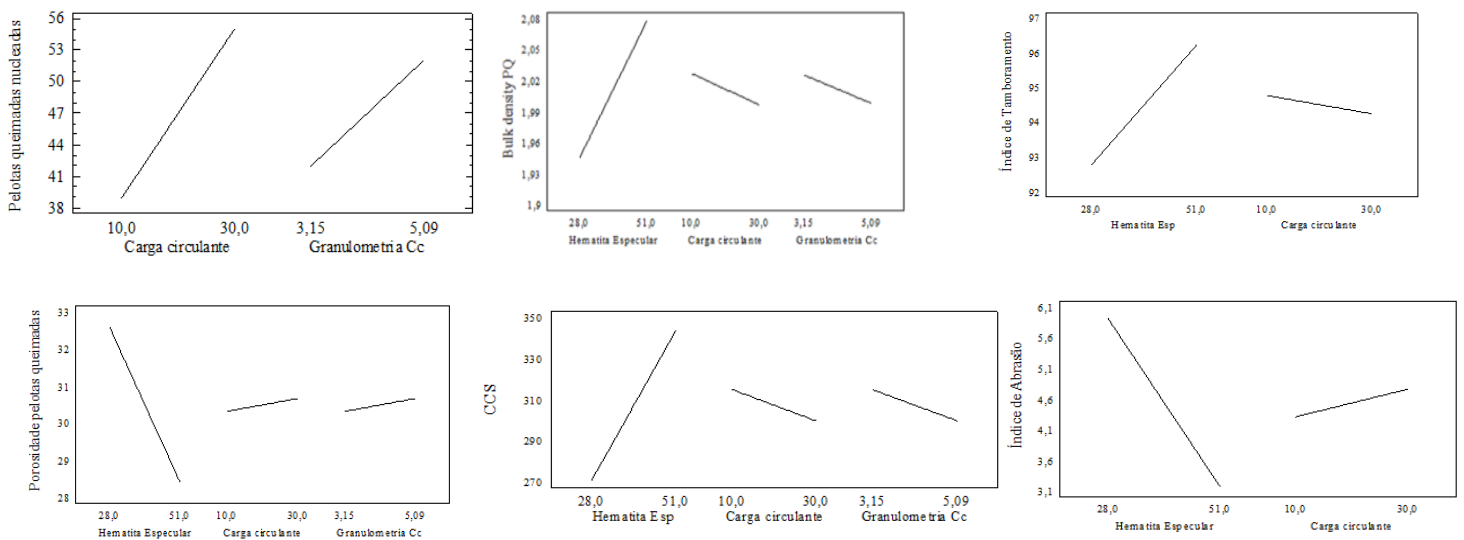

Figura 12. Interações dos Parâmetros de Qualidade Física das Pelotas Queimadas com os Fatores.

O teor de hematita especular influencia todas os parâmetros de qualidade física das pelotas cruas e queimadas, com exceção da quantidade de pelotas nucleadas. Em geral alto teor de hematita especular significa aumento da qualidade física da pelota crua e queimada. No mesmo sentido, em geral, reduzido percentual de carga circulante com granulometria mais fina também melhora a qualidade física das pelotas cruas e queimadas. Quanto maior o percentual de carga circulante com granulometria grossa aumenta a quantidade de pelotas nucleadas, reduzindo a resistência a compressão das pelotas queimadas. A Figura 13 apresenta uma pelota nucleada com trincas em torno do núcleo, mostrando fragilidade mecânica nesta região.

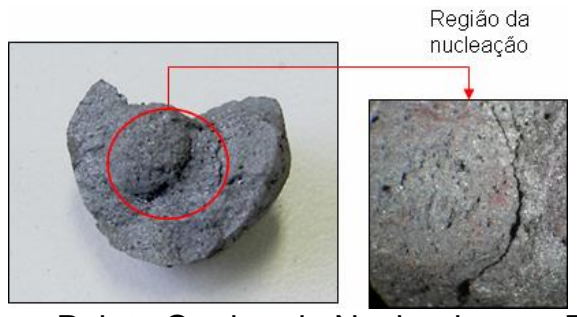

Figura 13. Estrutura de uma Pelota Queimada Nucleada com Trincas em torno do Núcleo.

A Tabela 5 apresenta os resultados de CCS para pelotas classificadas em nucleadas e não nucleadas

Tabela 5. Resistência à Compressão das Pelotas Queimadas Nucleadas e Não Nucleadas.

\begin{tabular}{c|c|c|c|c}
\hline Mineralogia (\%) & $\begin{array}{c}\text { Carga circulante } \\
(\%)\end{array}$ & $\begin{array}{c}\text { Granulometria carga } \\
\text { circulante }\end{array}$ & $\begin{array}{c}\text { CCS pelota sem } \\
\text { núcleo (kg/pelota) }\end{array}$ & $\begin{array}{c}\text { CCS pelota nucleada } \\
\text { (kg/pelota) }\end{array}$ \\
\hline HE alta & 10 & grosso & 342 & 320 \\
\hline HE baixa & 30 & fino & 288 & 265 \\
\hline HE alta & 30 & fino & 368 & 340 \\
\hline HE baixa & 30 & grosso & 289 & 249 \\
\hline HE média & 20 & médio & 324 & 300 \\
\hline HE baixa & 10 & grosso & 297 & 253 \\
\hline HE alta & 30 & grosso & 362 & 299 \\
\hline HE alta & 10 & fino & 397 & 320 \\
\hline HE baixa & 10 & fino & 299 & 259 \\
\hline HE alta & 10 & grosso & 359 & 310 \\
\hline HE baixa & 30 & fino & 275 & 263 \\
\hline HE alta & 30 & fino & 348 & 285 \\
\hline HE baixa & 30 & grosso & 269 & 248 \\
\hline HE média & 20 & médio & 316 & 285 \\
\hline HE baixa & 10 & grosso & 288 & 248 \\
\hline HE alta & 30 & grosso & 366 & 297 \\
\hline HE alta & 10 & fino & 392 & 339 \\
\hline HE baixa & 10 & fino & 286 & 238 \\
\hline & Média ponderada & & 328 & 284 \\
\hline & & & & \\
\hline
\end{tabular}

* Contribuição técnica ao 44 Seminário de Redução de Minério de Ferro e Matérias-primas, $15^{\circ}$ Simpósio Brasileiro de Minério de Ferro e 2º Simpósio Brasileiro de Aglomeração de Minério de Ferro, 15 a 18 de setembro de 2014, Belo Horizonte, MG, Brasil. 
As pelotas da Tabela 5 são as mesmas pelotas dos testes originais de resistência a compressão e mostram que as pelotas sem núcleo são mais resistentes que aquelas nucleadas. As pelotas nucleadas obtiveram uma média de resistência a compressão de $284 \mathrm{~kg} /$ pelota, enquanto que para as pelotas sem núcleo a média foi de $328 \mathrm{~kg} /$ pelota.

A Figura 14 apresenta um comparativo de microdureza de uma pelota nucleada e sem núcleo. A pelota sem núcleo 14(a) apresentou uma microdureza maior acima de 144HV enquanto que para a nucleada 14(b) valor mínimo de 31 e máximo de $115 \mathrm{HV}$.
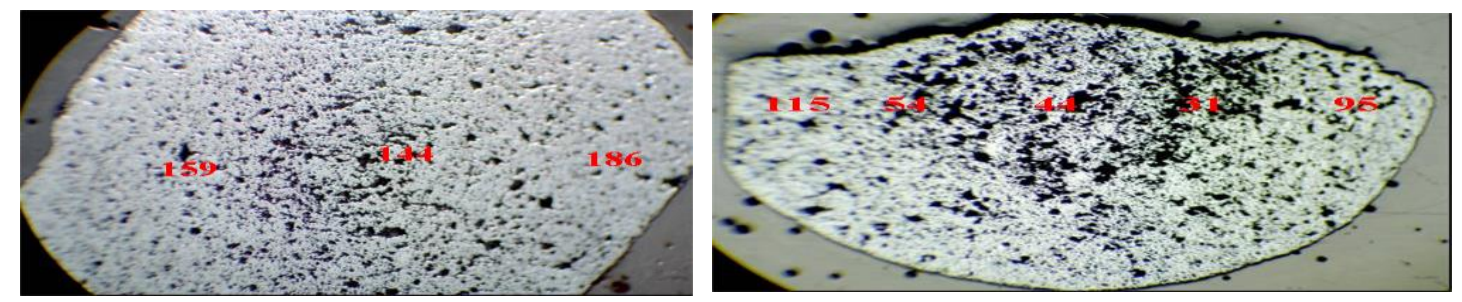

Figura 14 (a) CCS 322kg/pelota, sem Núcleo (Esquerda) (b) CCS 133kg/pelota, Nucleada (Direita)

\section{CONCLUSÕES}

Enumeram-se as principais conclusões desse trabalho:

- Os três fatores estudados influenciam os parâmetros físicos das pelotas cruas e queimadas, com exceção do percentual de pelotas nucleadas que foi influenciada pela granulometria e quantidade de carga circulante;

- O maior valor para o bulk density foi de $2,18 \mathrm{~g} / \mathrm{cm}^{3}$, obtido no teste com alto teor de hematita especular com baixo percentual de carga circulante com granulometria fina. $O$ valor médio para os testes com ponto central que utiliza dados atuais foi de $2,05 \mathrm{~g} / \mathrm{cm}^{3}$;

- O maior valor para o diâmetro médio foi de $11,5 \mathrm{~mm}$, obtido no teste com alto teor de hematita especular com baixo percentual de carga circulante com granulometria fina. $O$ valor médio para os testes com ponto central que utiliza dados atuais foi de $8,7 \mathrm{~mm}$;

- O maior valor para a resistência a compressão a úmido foi de $2305 \mathrm{~g} /$ pelota, obtido no teste com alto teor de hematita especular com baixo percentual de carga circulante com granulometria grossa. O valor médio para os testes com ponto central que utiliza dados atuais foi de $2137 \mathrm{~g} /$ pelota;

- O maior valor para a resistência a compressão a seco foi de $10445 \mathrm{~g} /$ pelota, obtido no teste com alto teor de hematita especular com baixo percentual de carga circulante com granulometria fina. $O$ valor médio para os testes com ponto central que utiliza dados atuais foi de $7557 \mathrm{~g} /$ pelota;

- O menor valor para o percentual de pelotas nucleadas foi de $29 \%$, obtido no teste com baixo teor de hematita especular com baixo percentual de carga circulante com granulometria fina;

- O menor valor para a porosidade foi de $28,1 \%$, obtido no teste com alto teor de hematita especular com baixo percentual de carga circulante com granulometria fina. $O$ valor médio para os testes com ponto central que utiliza dados atuais foi de $30,7 \%$;

- O maior valor para o bulk density foi de $2,12 \mathrm{~g} / \mathrm{cm}^{3}$, obtido no teste com alto teor de hematita especular com baixo percentual de carga circulante com granulometria fina. $O$ valor médio para os testes com ponto central que utiliza dados atuais foi de $2,02 \mathrm{~g} / \mathrm{cm}^{3}$;

* Contribuição técnica ao 44ํㅗㄴ Seminário de Redução de Minério de Ferro e Matérias-primas, $15^{\circ}$ Simpósio Brasileiro de Minério de Ferro e 2º Simpósio Brasileiro de Aglomeração de Minério de Ferro, 15 a 18 de setembro de 2014, Belo Horizonte, MG, Brasil. 
- O maior valor para a resistência a compressão a seco foi de $375 \mathrm{~kg} / \mathrm{pelota}$, obtido no teste com alto teor de hematita especular com baixo percentual de carga circulante com granulometria fina. $O$ valor médio para os testes com ponto central que utiliza dados atuais foi de $306 \mathrm{~kg} /$ pelota;

- O maior valor para o índice de tamboramento foi de 96,8\%, obtido no teste com alto teor de hematita especular com baixo percentual de carga circulante com granulometria fina. $O$ valor médio para os testes com ponto central que utiliza dados atuais foi de $95,5 \%$;

- O menor valor para o índice de abrasão foi de 2,78\%, obtido no teste com alto teor de hematita especular com baixo percentual de carga circulante com granulometria fina. $O$ valor médio para os testes com ponto central que utiliza dados atuais foi de $3,7 \%$;

- A diminuição do percentual de carga circulante conjugada com a sua desagregação reduz o impacto da perda de qualidade física quando se utiliza minérios com baixos teores de hematita especular;

- O teor de umidade das pelotas cruas coletadas na planta industrial varia de acordo com o seu tamanho. Pelotas cruas com tamanho entre $8 \mathrm{~mm}$ e $6,3 \mathrm{~mm}$ tem umidade de $8,5 \%$, enquanto que pelotas entre $16 \mathrm{~mm}$ e $9 \mathrm{~mm}$ tem umidade de $9,8 \%$;

- Os testes de dureza e micrografia ótica mostraram que na região da superfície do núcleo há uma maior formação de poros que reduziu consideravelmente a resistência mecânica das pelotas queimadas.

\section{REFERÊNCIAS}

1 Costa AGD. Caracterização dos parâmetros intrínsecos de porosidade pelo método de Adsorção de Nitrogênio de Concentrados Remoídos de Minérios Itabiríticos do Complexo Alegria. 113 páginas. Dissertação de Mestrado, REDEMAT - Ouro Preto, 2005.

2 Meyer K. Pelletizing of Iron Ores - Springer - Verlag Berlin, Heidelberg, and Verlag Stahleissen mbH, Düsseldorf, Germany, 21-205, 1980.

3 Cota MF. Influência da distribuição granulométrica do pellet feed no processo de aglomeração e na qualidade da pelota de minério de ferro para redução direta. 142 páginas. Dissertação de Mestrado, REDEMAT - Ouro Preto, 2004.

4 Iveson SM, Hott S, Biggs S. Advancing contact angle of iron ore as a function of theirs hematite and goethite content: implication for pelletising and sintering. Department of Chemical Engineering, University of BNewcastle, Callaghan, Austrália, 2004.

5 SÁ KG. Estudo da influência da mineralogia dos tipos de minério da Samarco Mineração sobre a resistênica a compressão de pelotas para processos de redução direta. 86 páginas. Dissertação de Mestrado, REDEMAT - Ouro Preto, 2003.

6 Nishida R, Imanishi N, Ohtsuki K. Effect of particle size on the balling of iron ores and on physical properties of green pellets - Proceedings ICSTIS, Suppl. Trans. ISIJ, 1971; 11(1).

7 Rumpf $\mathrm{H}$. - the strength of granules and agglomerates in agglomeration - Interscience, New York, páginas 379-418, 1962.

8 Sportel H, Droog J - Quality of green iron ore pellets - Iron making and Steelmaking, 1997; 24(2): 129-132.

9 CAPES CE. Particle size enlargement. Handbook of powder technology, vol1. Elsevier, p. 1-73, 1980.

* Contribuição técnica ao 44ำ Seminário de Redução de Minério de Ferro e Matérias-primas, $15^{\circ}$ Simpósio Brasileiro de Minério de Ferro e $2^{\circ}$ Simpósio Brasileiro de Aglomeração de Minério de Ferro, 15 a 18 de setembro de 2014, Belo Horizonte, MG, Brasil. 